Nuntius Antiquus, Belo Horizonte, v. 13, n. 2, p. 195-213, 2017

\title{
Os paradoxos do início da metafísica moderna
}

\section{The Paradoxes of Early Modern Metaphysics}

\author{
Nastassja Pugliese \\ Departamento de Filosofia \\ Universidade de São Paulo, São Paulo, São Paulo / Brasil \\ nastassjapugliese@usp.br
}

Resumo: Este artigo é uma análise da influência dos paradoxos na história da filosofia e, mais especificamente, sobre como certo conjunto de paradoxos orientam as discussões metafísicas do começo da modernidade. O objetivo é mostrar que a metafísica do século XVII é marcada por três paradoxos que estão interligados. A hipótese aqui é a de que eles são versões do mesmo problema metafísico, o problema do um e do múltiplo, mas construídos segundo diferentes formulações: a teológica, a científica e a matemática. Para esse fim, essas formulações do paradoxo serão reconstruídas de acordo com o modo como estão presentes na metafísica de Spinoza, Descartes e Leibniz. Esta análise sugere que os paradoxos cumprem um papel fundamental não apenas na exposição dos problemas filosóficos da história da filosofia mas também nas investigações filosóficas. A vantagem de se apresentar os problemas filosóficos na forma de paradoxos é que eles capturam mais facilmente o intelecto, estimulando a mente a deter-se sobre eles.

Palavras-chave: paradoxos; filosofia moderna; metafísica.

Abstract: This paper is an analysis of the influence of paradoxes in the history of philosophy, more specifically, on how a certain set of paradoxes shape the metaphysical discussions of Early Modernity. The goal of the paper is to show that the metaphysics of the Seventeenth Century is marked by three paradoxes that are intertwined. The hypothesis here is that these three paradoxes are versions of the same metaphysical problem, the one and many problem, but offered in three different formulations: the theological, the scientific, and the mathematical. To this end, the formulations are going to be reconstructed according to the way they are present in the metaphysical works of Spinoza, Descartes, and Leibniz. This analysis will suggest that paradoxes play a fundamental role not only in exposing the philosophical problems in the context 
of the history of philosophy, but they also fill an important methodological role in philosophical investigations. The advantage of presenting philosophical problems in the form of paradox is that paradoxes capture the intellect more easily, stimulating the mind to think thorough them.

Keywords: paradoxes; Early Modern philosophy; metaphysics.

A princípio, e sob a perspectiva lógico-argumentativa, considerase que paradoxo é uma denominação atribuível a um conjunto, unitário ou não, de afirmações que acreditamos absurdas, inconsistentes ou impossíveis que podem ser derivadas de uma interpretação determinada de uma situação ou de um fato qualquer. Essa formulação geral indica que os paradoxos dependem tanto de nossas crenças sobre o que é ou não absurdo quanto do modelo de interpretação que tomamos como critério de interpretação das afirmações que podemos fazer sobre o mundo. Algumas afirmações são paradoxais segundo certo contexto teórico ou visão de mundo, mas não o são no caso de outros. Do mesmo modo, algumas afirmações são paradoxais segundo determinado contexto formal e não o são segundo outro contexto formal. Desse modo, podemos dizer que paradoxos possuem ao menos duas origens, podendo surgir pela combinação de premissas (ou axiomas de nossas teorias) que versam sobre algum conteúdo material, ou podem surgir por causa de conflitos entre critérios de interpretação formal. ${ }^{1}$ Os paradoxos que nos interessam

\footnotetext{
${ }^{1}$ A classificação mais aceita de paradoxos é a oferecida em 1906, por Russell, que classifica os paradoxos entre paradoxos lógicos e paradoxos semânticos. É importante destacar que há outras classificações possíveis acerca das origens dos paradoxos como, por exemplo, a classificação de Peano (1906), que, em resposta à Russell, distingue entre paradoxos linguísticos e paradoxos matemáticos (LANDINI, 2004). Há também a classificação de Quine, que, em "The Ways of Paradox", seu pequeno tratado sobre o tema, distingue entre paradoxos veridicus e paradoxos falsidicus. Os primeiros são aqueles em que ambas as proposições que formam o paradoxo são verdadeiras, e a conjunção delas resulta em uma sentença absurda, porém igualmente verdadeira. O exemplo dado para ilustrar esse caso é o paradoxo do aniversário de Frederic, protagonista da ópera "Os Piratas de Penzance ou Os Escravos do Poder". Frederic nasceu em 29 de fevereiro. Assim, depois de 21 anos desde o ano de seu nascimento, ele conta cinco aniversários mas 21 anos de idade. A situação é nitidamente absurda e
} 
aqui são os que surgem quando conjugamos certas afirmações que consideramos como materialmente verdadeiras, ou seja, que surgem das experiências das coisas reais e da nossa tentativa de descrever como elas são. Um exemplo desse tipo de paradoxo é o paradoxo de Sorites: quando assumimos como verdadeiro que um monte é uma coleção de grãos de areia e também aceitamos como parte de nossas crenças (ou premissas) que um grão de areia não forma um monte e nem dois grãos de areia e nem quatro, etc., chegamos à conclusão de que não há quantidade de areia que forme um monte. Tal paradoxo ocorre, pois tomamos como verdadeiro um conjunto de afirmações que é inconsistente ou, como é o que ocorre neste caso, quando temos uma afirmação com um termo vago que não admite uma definição precisa, levando, portanto, a formulações inconsistentes.

No que diz respeito à sua estrutura, no entanto, os paradoxos se assemelham. Apesar de nem todo paradoxo ou situação paradoxal conter, à primeira vista, uma contradição, eles podem ser reconstruídos

paradoxal, mas nesse caso, a conclusão de que Frederic passou 5 aniversários mas tem 21 anos não é contraditória. Há um argumento que explica a verdade de tal proposição. Por seu turno, os paradoxos falsidicus não são tão fáceis de resolver; seu exemplo paradigmático é uma versão do paradoxo do barbeiro, enunciado por Russell em uma versão mais branda, em 1918. Neste paradoxo, que termina com uma pergunta, ambas as respostas causam problemas. A formulação é a seguinte: "em uma certa vila, há um homem que é barbeiro, este barbeiro barbeia todos e apenas aqueles homens na vila que não barbeiam a si mesmos. Pergunta: o barbeiro barbeia a si mesmo?" Este paradoxo leva a duas conclusões inaceitáveis ou a uma redução ao absurdo que indica que há algum elemento falso da descrição da situação. Em ambos os paradoxos, uma conclusão absurda é tida como verdadeira, mas, no primeiro, há uma explicação para a verdade da conclusão. No segundo, o caráter absurdo da conclusão mostra que há uma falsidade nas premissas. Quine ainda considera que os paradoxos não são exauríveis nessas duas categorias. Quando os paradoxos são mais graves e nos obrigam a considerar falsas crenças já enraizadas, ele os chama de antinomias. Quine trata dos paradoxos, neste ensaio, segundo três eixos: o da relatividade do caráter paradoxal de uma proposição, dado o contexto histórico de uma determinada doxa, o do caráter gradual dos paradoxos, medido pela amplitude das revisões que a resolução de determinados paradoxos nos obriga a realizar em nossos sistemas de crenças, e a fecundidade dos paradoxos, que demonstra a intensidade das pesquisas que deles surgem (GALINON, 2009). Para uma introdução ao tema, ver o verbete "Paradoja" (PENÃ; AUSÍN, 2011, p. 442). 
de modo que a contradição ou a aparente contradição seja explicitada. Podemos dizer, depois de detalhadas as sentenças causadoras da situação paradoxal, que paradoxos ocorrem quando há a afirmação simultânea da verdade de duas (ou mais) proposições que não podem ser (ou não deveriam ser) simultaneamente verdadeiras. As proposições que formam um paradoxo podem ser verdadeiras e plausíveis, se tomadas de modo independente umas das outras, mas se interpretadas de uma vez só como um conjunto, tornam-se problemáticas e, por vezes, tal conjunção pode resultar em uma sentença falsa e, consequentemente, em uma contradição. É a interpretação simultânea de duas proposições independentes que gera, portanto, a situação paradoxal, qual seja: considera-se que A é verdadeiro e B é verdadeiro, mas percebe-se que A \& B não é necessariamente verdadeiro. Tal situação descreve a forma lógica geral dos paradoxos. Paradoxos, portanto, enunciam situações problemáticas ou absurdas que exigem maiores explicações, porque trazem em si uma potencial contradição. Digo potencial contradição e não contradição per se, porque paradoxo não é sinônimo de contradição, mas de confronto ou o conflito entre razões (ou percepções) contrárias. Se tal conflito é entre razões (ou sentenças) para as quais temos evidências fortes o suficiente para considerarmos ambas verdadeiras, então o paradoxo ganha o nome de antinomia ou aporia (PENÃ; AUSÍN, 2011, p. 442). Se o conflito é entre razões que, depois de um exame atento, podem ser revistas e consideradas, conjuntamente, consistentes, então temos um paradoxo com aparente contradição. Tais paradoxos, entretanto, não são necessariamente menos fecundos que as antinomias ou aporias só porque não contêm uma contradição. Todos os paradoxos são desafiadores na medida em que exigem o exercício da razão para a revisão de nossas expectativas racionais e demandam, eventualmente, a ressignificação de conceitos que tomávamos como bem estabelecidos. Assim, sejam eles portadores de contradições genuínas ou apenas de contradições aparentes, paradoxos são problemas que forçam a razão a voltar sobre si mesma e a buscar por mais (e melhores) explicações. Esse efeito ocorre porque as potenciais contradições para as quais os paradoxos apontam indicam, por sua vez, a existência de um provável erro de entendimento (ou mesmo 
ausência de entendimento) no conjunto de nossas crenças ou das coisas conhecidas. Desse modo, podemos dizer que paradoxos não são somente conclusões absurdas, inconsistentes ou impossíveis, ou seja, enunciados que afrontam o que acreditamos ser verdadeiro, mas são também indícios de questões genuínas que marcam inícios de investigações.

Considerando-se que os paradoxos apresentam uma mesma estrutura lógica fundamental e que, ainda assim, não são todos iguais tendo em vista suas origens e o seu conteúdo semântico, segue-se que paradoxos diferem também em relação ao seu poder causal. Paradoxos têm efeitos distintos no conhecimento e, como dito anteriormente, essa diferença não se dá por causa da ausência ou não de contradição. Paradoxos têm sempre algum grau de poder causal no pensamento, pois exigem que a razão se debruce sobre ele. Afinal, se as razões que dão origem ao paradoxo não forem examinadas com cuidado, não há como saber, de antemão ou à primeira vista, se a contradição trazida por ele pode ser resolvida ou não. É preciso, portanto, que a razão se detenha sobre o paradoxo para decidir se há necessidade de revisão de determinadas crenças. Há paradoxos mais ou menos devastadores, mais ou menos subversivos, no que diz respeito aos seus efeitos epistemológicos e políticos. Assim, nem todo paradoxo é atemporal e nem todo paradoxo é indissolúvel, mas aqueles que o são, são também fontes de investigação e origem de mudanças históricas profundas. Os paradoxos que serão tratados aqui - por serem paradoxos próprios da metafísica, ou seja, da investigação do ser enquanto ser, ou da investigação sobre os princípios primeiros, como define Aristóteles - têm origem nos axiomas que fundamentam as respectivas teorias metafísicas. Por se originarem nas verdades mais primevas e fundamentais que sustentam as teorias filosóficas, a revisão conceitual que os paradoxos metafísicos exigem é compreensiva e pode levar ao desmonte do edifício teórico-conceitual estabelecido. Jorge Luis Borges, o mestre dos labirintos e paradoxos na literatura, no artigo La esfera de Pascal, anuncia: "quizá la história universal es la historia de unas quantas metáforas", 2 ao que aqui, com a

2 "La Esfera de Pascal" (BORGES, 2011). 
devida adaptação, torna-se parte da presente hipótese de trabalho: talvez a história da filosofia seja a história de uns tantos paradoxos.

Os paradoxos metafísicos que inauguram a modernidade possuem um duplo caráter. Se por um lado, eles são formulações muito precisas de certas questões filosóficas atemporais, por outro, as formulações dos paradoxos demonstram interesses de investigação e estratégias de solução que são próprias de determinados contextos históricos. Assim, a história da filosofia não é exatamente a história de uns tantos paradoxos, mas é, na verdade, a história das diferentes interpretações de certos paradoxos. ${ }^{3}$ Os paradoxos que marcam o começo da metafísica moderna, e que aqui são chamados "inaugurais", são antinomias tradicionais, problemas próprios da metafísica que surgem concomitantemente com esse tipo de investigação. $\mathrm{O}$ caráter inaugural dos paradoxos que aqui chamamos de "modernos" ocorre na medida em que é possível perceber um esforço coletivo de enfrentamento dessas questões particulares segundo uma determinada tendência de resolução deles, de modo que se pode dizer que tal tendência e tais problemas orientam as investigações filosóficas do período. O engajamento com esses paradoxos-questões gera mudanças profundas, e tais mudanças exigiram uma reorientação conceitual de proporções históricas, que acabou por demarcar a época. Desse modo, deve-se considerar os paradoxos não como sinais dos limites do conhecimento, mas como fontes profícuas de investigações filosóficas e índices de dificuldades teóricas que estimulam a busca pelo conhecimento.

Quando a história da filosofia moderna é estudada com base em tais índices, percebe-se que a metafísica do século XVII é marcada pelo entrelaçamento de três paradoxos que, em um certo sentido, são versões de uma mesma questão. O fato é que os paradoxos metafísicos do começo da modernidade são, eles mesmos, versões do problema da unidade e da multiplicidade em três diferentes formulações: a teológica, a científica (ou física) e a matemática. Exemplos de tais formulações

\footnotetext{
${ }^{3} \mathrm{O}$ conto começa com a frase citada no corpo do nosso artigo e termina com uma reformulação da mesma frase: "Quizá la historia universal es la historia de la diversa entonación de algunas metáforas" [grifo nosso].
} 
podem ser encontrados em várias obras do período, mas a presente análise se deterá sobre a obra dos três principais filósofos racionalistas: a formulação teológica do problema do uno e do múltiplo pode ser observada na primeira parte da Ética de Espinosa, na qual se investiga a natureza de Deus e sua identificação com a substância; já a formulação científica, relativa à natureza da matéria e à possibilidade de movimento dos corpos, encontra-se na física de Descartes (aqui representada de modo parcial pelas obras Meditações Metafísicas e Princípios de Filosofia); e a formulação matemática, por sua vez, é evidenciada na obra de Leibniz, em sua correspondência com Arnauld e nos opúsculos Verdades Primeiras, Discurso de Metafísica e Sistema Novo da Natureza. Comecemos pela formulação teológica apresentada por Espinosa.

Espinosa, o lavrador de cristais e sonhador de labirintos, como o descreve J-L Borges, ${ }^{4}$ constrói uma obra que, por ser escrita analiticamente segundo o método geométrico, ilustra as aspirações da época, de sistematização e unidade do conhecimento. Na primeira parte da Ética, intitulada “Sobre Deus", Espinosa trata da formulação teológica da questão do uno e do múltiplo e defende o monismo como solução.

\footnotetext{
${ }^{4}$ Borges escreveu o poema "Spinoza", no qual o chama de lavrador de cristais. Espinosa era polidor de lentes e sua ocupação o tornou célebre. A metáfora do cristal conjuga tal ocupação com a estrutura geométrica da Ética. O poema:
}

Las traslúcidas manos del judío

Labran en la penumbra los cristales

Y la tarde que muere es miedo y frío.

(Las tardes a las tardes son iguales.)

Las manos y el espacio de jacinto

Que palidece en el confín del Ghetto

Casi no existen para el hombre quieto

Que está soñando un claro laberinto.

No lo turba la fama, ese reflejo

De sueños en el sueño de otro espejo,

$\mathrm{Ni}$ el temeroso amor de las doncellas.

Libre de la metáfora y del mito

Labra un arduo cristal: el infinito

mapa de Aquel que es todas Sus estrellas.

Em “ El otro, el mismo" (BORGES, 2011). 
É em um de seus primeiros escritos, o Breve Tratado, no "Diálogo entre o Intelecto, o Amor, a Razão e Concupiscência", que o problema é inicialmente colocado e analisado com a hesitação própria com que filósofos tratam aporias. No diálogo, quem o enuncia é a concupiscência, a cobiça: "Seria certamente admirável se isto fosse consistente: que a Unidade concorde com a Diversidade que eu, em toda parte, vejo na Natureza. Porém, como pode?". ${ }^{5}$ O problema do uno e do múltiplo, segundo a visão da cobiça, é uma contradição indissolúvel, afinal, como pode a Natureza ser uma só e ao mesmo tempo tão diversa? Esse problema será tratado por Espinosa em diversos escritos e terá sua proposta de solução apresentada na Ética.

O paradoxo com o qual Espinosa engaja é recorrente das discussões teológicas do helenismo e da escolástica: como pode um deus uno, sumamente perfeito, que não necessita de nada para ser o que é, gerar seres diferentes dele mesmo, que são imperfeitos, dependentes e múltiplos? Se deus é sumamente perfeito, dele não se pode derivar imperfeição. Se os homens são criaturas imperfeitas, então, ou não foram criados por deus ou deus não é sumamente perfeito. Essa formulação admite e é tratada em suas variações, como, por exemplo, o problema do mal, presente em suas correspondências com Blyenbergh: se deus é benevolente, por que há o mal? O paradoxo teológico como tratado por Espinosa é, entretanto, formulado de modo mais geral: se deus é de natureza diferente das criaturas, então deus não pode ter sido causa da criação das criaturas, porque uma substância não pode produzir outra substância sem que ambas tenham atributos em comum (E1p6, E1p2). Mas se as criaturas compartilham atributos com o criador, então ou criador e criatura são uma mesma substância ou são duas substâncias distintas. Mas toda substância é necessariamente infinita (E1p8) e não pode ser,

\footnotetext{
${ }^{5}$ Tradução minha do inglês. Ver KV G I 28/20-25 em Curley (1985, p.74). Há uma tradução do Breve Tratado em Português, lançada pela Editora Autêntica, feita por Fragoso e Oliva (2014). Nela se lê: "Concupiscência: Um momento! Soa admiravelmente que a unidade e a diversidade, que eu vejo por qualquer parte da Natureza, concordem entre si. Porém, como?"
} 
portanto, limitada por outra de mesma natureza (E1p7). ${ }^{6}$ Portanto, todo atributo só pode pertencer a uma única substância, não podendo haver duas substâncias com o mesmo atributo e, portanto, deus e criatura não podem pertencer a substâncias distintas. Se esse é o caso, então é necessário que deus e a criação compartilhem da mesma substância. Se deus e as coisas criadas são uma mesma substância, então é preciso que essa substância seja causa de si mesma e seja absolutamente infinita. Se o argumento parasse por aqui, ele já poderia ser considerado paradoxal, pois a afirmação ou o resultado de que deus e a criatura compartilham da mesma substância entra em conflito com a opinião tomada como verdadeira à época. Entretanto, ao seguirmos com o argumento, chegamos a uma formulação ainda mais complicada, apontada por Bayle e Hegel em suas críticas a Espinosa: se é o caso que há apenas uma única substância, então à natureza da substância pertence o existir (E1p7), ou seja, a substância única existe e é a única coisa que há. Ou, formulando de outro modo: se deus e a criatura são uma e mesma coisa, e deus é que tem o poder absolutamente infinito, então a única coisa que há é deus. Espinosa argumenta pela existência da unidade, mas e o múltiplo? Como justificar a produção da multiplicidade dado que só a substância existe verdadeiramente? A Ética pretende oferecer uma solução para tal dificuldade, mas, dada a opinião comumente difundida à época de um deus criador, imaterial, distinto de sua criação e que legisla sobre ela, os argumentos oferecidos por Espinosa são, como ele mesmo diz a Blyenbergh, "de difícil digestão". ${ }^{7}$ Espinosa propõe a existência de uma única substância com infinitos atributos, que, agindo sobre si mesma com seu poder absoluto e infinito, modifica-se, gerando, assim, infinitos modos que são, por sua vez, diversos entre si. A substância que existe de modo único e absoluto é identificada com deus, e este, por seu turno, é identificado com a natureza (produzida e producente). Se deus é natureza, e a multiplicidade é constituída por uma substância única, então tudo o

\footnotetext{
${ }^{6}$ Para mais referências, ver também Fragoso (2015, p.11-31 E.A. R.).

${ }^{7}$ Espinosa, quando procura rebater os argumentos dos filósofos modernos e escolásticos a respeito da natureza de deus e da natureza da vontade de deus, chama-os de “argumentos de difícil digestão" (KORICHI, 2006, p. 125).
} 
que há é modificação de um mesmo ser. É importante notar que, apesar de Espinosa tratar da questão do uno e do múltiplo com base em sua formulação teológica, ou seja, considerando a unidade como deus e o múltiplo como as coisas criadas, seu interesse é menos o de resolver e mais o de minimizar o caráter propriamente teológico da questão (NADLER, 2011, p. 167). ${ }^{8}$ Assim, Espinosa procura desfazer os efeitos da superstição e da crença em um deus criador e transcendente, tratando da relação entre o um e o múltiplo, ou do problema da relação entre deus e as criaturas, de modo imanente, ou seja, em termos de natureza e substância. A formulação teológica de Espinosa e seu engajamento com ela inaugura o processo de laicização da filosofia após séculos de intercessão entre tal formulação e a teologia, fato esse que marca as tendências filosóficas da modernidade.

Já Descartes, um dos principais interlocutores de Espinosa, inclina seus argumentos para o outro lado da balança do paradoxo teológico, modificando, portanto, o locus do problema. Como é argumentado nas Meditações, deus e criaturas não compartilham da mesma substância. Deus é definido como tendo apenas um atributo, o atributo pensamento, e as criaturas são definidas como partícipes do atributo pensamento, além de serem constituídas pelo atributo extensão. O problema da formulação de Descartes, no que diz respeito ao paradoxo em sua formulação teológica, é explicar como deus, enquanto atributo pensamento, cria a extensão, e como, posteriormente, os pensamentos dos indivíduos (ou seja, suas

\footnotetext{
8 "If pressed to name a single issue that was most central to philosophy on the Continent in the second half of the Seventeenth Century, I would have to say, with little hesitation: theodicy and the problem of evil. A plausible case can be made, I believe, for the claim that the question of the origin of and explanation for the existence of evil, sin and suffering in a world created by an omnipotent, omniscient, wise, and benevolent God-as well as the apparent injustice in the distribution of grace by a necessarily just God who, Scripture says, wants everyone to be saved - is what most exercised the great philosophical minds of the period. This is most obviously true for such thinkers as Malebranche and Arnauld, but it is also true for someone with so wide a diversity of interests as Leibniz. It is even true, in a sense, for Spinoza, although in a very different way: Rather than trying to solve the conundrum, he hoped to diminish the general concern with such questions by undermining the anthropomorphic and superstitious beliefs which nourished them." (NADLER, 2011, p. 167).
} 
mentes) podem mover coisas extensas, dado que pensamento e extensão são duas substâncias distintas que, a princípio, nada compartilham.

Tanto Espinosa quanto Descartes compartilham da noção aristotélica de que conhecer é conhecer pelas causas, ou seja, explicar é determinar a causa. Além disso, compreendem que todo efeito possui alguma coisa em comum com a sua causa, ou seja, uma coisa só pode ser causa de outra, se elas compartilharem de alguma característica em comum. Conjugando ambos princípios, temos que só as coisas com as quais compartilhamos alguma característica nos são inteligíveis. Disso se segue que se a mente é constituída por uma substância completamente diferente daquela do corpo, não só a mente é incapaz de mover o corpo como também o corpo e, por conseguinte, tudo o que é material não é inteligível. Logo, a natureza da matéria, enquanto substância separada do pensamento, não é inteligível. Por isso, o problema do uno e do múltiplo como ele se apresenta em Descartes pode ser considerado como uma elaboração nos termos da ciência da Física: há uma única matéria, ou seja, uma única substância extensa que ocupa o espaço, e que, ao mesmo tempo em que é una, é ocupada por uma multiplicidade de corpos distintos. ${ }^{9}$ Sua concepção de matéria exclui a possibilidade de existência do vácuo ou, seja, de algum espaço que não seja preenchido pela extensão. A extensão é, portanto, a união dos espaços ocupados pelos corpos. Como definido nos Princípios de Filosofia, "a extensão em largura, comprimento e profundidade que constitui o espaço ocupado por um corpo é exatamente a mesma que constitui o corpo". Ou seja, a extensão enquanto substância é o preenchimento total do espaço pela multiplicidade dos corpos, sem que haja espaço entre tais corpos. O problema dessa formulação é como explicar a origem da multiplicidade de corpos em um plenum (a extensão enquanto substância), dado que Descartes rejeita as explicações atomistas e defende que, já que a matéria é infinitamente divisível em pensamento, ela também deve ser infinitamente divisível em sua natureza enquanto extensão. A matéria, em Descartes, é um todo unificado, considerado como substância, que é, portanto, infinitamente divisível.

\footnotetext{
9 "the extension in length, breadth, and depth which constitutes the space occupied by a body, is exactly the same as that which constitutes the body" (Pr II 10) (SLOWIK, 2014).
} 
Dados os argumentos das Meditações e dos Princípios de Filosofia, vê-se que a originalidade do problema tratado por Descartes não está exatamente no modo como ele trata o paradoxo da unidade e da multiplicidade em sua formulação teológica. Afinal, o conceito de deus de Descartes ainda traz elementos tradicionais e de inspiração escolástica. A originalidade do filósofo está em seu tratamento do problema da unidade e da multiplicidade no que diz respeito à natureza da matéria. Por isso, ele inaugura a metafísica moderna com a versão científica, ou melhor, física, do paradoxo do uno e do múltiplo. Tal formulação do paradoxo o leva, então, a desenvolver uma física procurando estabelecer as leis gerais dos movimentos dos corpos. O movimento é definido nos Princípios de Filosofia como sendo "a transferência de um pedaço de matéria ou de um corpo, da vizinhança de tais corpos imediatamente contíguos a ele e considerados em repouso, para outros corpos vizinhos", ou seja, a mudança na vizinhança de corpos contíguos, ou no local externo do corpo que é movido. O problema do movimento, como vimos, surge de sua concepção de matéria como substância unificada e como propriedade de uma multiplicidade de corpos: como é possível o movimento de corpos discretos, dado que os corpos, eles mesmos, formam uma unidade substancial única? Essa disposição ontológica da matéria e as explicações sobre a possibilidade de movimento no interior do plenum ficaram conhecidas como mecanicismo. Mas essa definição de causalidade mecânica ou linear não é isenta de contradições e inaugura, portanto, um caminho de pesquisa filosófica e científica, já que tal explicação sobre a física dos corpos é insuficiente.

O outro aspecto do problema da unidade e da multiplicidade que compõe a hipótese explicativa deste trabalho é a formulação matemática deste paradoxo. Essa formulação é fruto do engajamento de Leibniz com o caráter lógico-metafísico da questão. É importante salientar, porém, que, assim como Espinosa e Descartes, as questões metafísicas do modo como são tratadas por Leibniz evidenciam o fato de que a modernidade é inaugurada com o afastamento da filosofia e da teologia, sendo que a primeira começa a tornar-se independente da segunda. Com Leibniz, vê-se o fortalecimento das relações entre a filosofia e a lógica, e entre 
a filosofia e a matemática. Leibniz traz a estratégia logicista para o campo da investigação metafísica, dado que sua teoria das substâncias individuais é uma solução proposta para o problema do contínuo na matemática. Na obra Sobre a Liberdade, Leibniz enuncia: "há dois labirintos na mente humana; um diz respeito à composição do contínuo e o outro à natureza da liberdade", ${ }^{10}$ de modo que "ninguém chegará a uma filosofia verdadeiramente sólida sem que tenha passado por este labirinto [o do contínuo]." "11 A metafísica de Leibniz enunciada na Monadologia é resultado de várias reflexões e tentativas de resolução do problema do contínuo, ${ }^{12}$ considerado por Leibniz, portanto, como o mais importante e mais difícil problema filosófico a ser enfrentado.

O paradoxo do contínuo é, portanto, o problema do uno e do múltiplo em sua versão lógico-metafísica. Em sua versão estritamente matemática, o paradoxo é o seguinte: se um ponto é definido como aquilo que não possui extensão, como é possível uma linha, que é extensa, ser composta por um infinito número de pontos não extensos? A definição de ponto como aquilo que não tem parte, dada por Euclides, sofreu objeção de Aristóteles, que apontou que aquilo que não tem partes não pode compor um todo contínuo. Assim, Leibniz procura compreender a natureza do ponto de um modo alternativo e o define como "fronteira" ou "limite", ou seja, como aquilo que não possui extensão e cujas partes são não distantes. O contínuo é, portanto, uma entidade que mantém suas partes unidas, de modo que não haja descontinuidade (ou vazio) entre elas. O contínuo, que, neste caso estritamente matemático, é representado pela reta, e no caso metafísico, pela substância, é um plenum, ou seja, uma unidade. Portanto, o paradoxo do contínuo também ocorre quando começamos com uma reta e procuramos chegar até um ponto: se uma reta é um contínuo ou um plenum, então ela é divisível ao infinito. Mas se uma reta pode ser infinitamente divisível, ela não pode ser composta por pontos, sejam estes pontos unidades indivisíveis ou unidades que sejam

\footnotetext{
${ }^{10}$ Ver Parkinson (1973, p. 107).

${ }^{11}$ Ver Arthur (2001).

${ }^{12}$ Russell afirma que "Leibniz diz ter deduzido a existência e a natureza das mônadas em sua maior parte da necessidade de explicar o contínuo". (RUSSELL, 1992, p.108).
} 
determinadas por "limites". Esse problema reflete também o paradoxo do movimento da matéria em Descartes, pois se não há espaços entre os indivíduos ou entre as unidades individuais, então como é possível a transferência de movimento entre estes corpos? Como pode um corpo, em um plenum, estar em repouso? E como pode tal corpo começar a se mover, dado que ele existe em um contínuo?

Leibniz procura solucionar tal problema, resgatando a noção aristotélica de substância individual, mas retirando dela seu caráter material. Mônadas não são materiais, mas abstrações da unidade do indivíduo que é, portanto, indivisível e indestrutível. Suas primeiras formulações da noção de substância individual ocorrem no Discurso de Metafísica e na correspondência com Arnauld, nos quais trata desta noção como sendo análoga ao conceito de ponto. Mas ao estabelecer tal analogia, Leibniz precisa complexificar sua metafísica para acomodar a comensurabilidade entre os campos da física (substância individual) e da matemática (ponto). As investigações metafísicas de Leibniz, no processo de transformar um problema tradicionalmente tratado em conjunção com a teologia em uma questão matemática, resultaram em uma inovação matemática que se tornou um instrumento fundamental: o cálculo infinitesimal. Portanto, a questão da definição de um indivíduo (ou de uma substância individual) face ao problema do contínuo é que ela exige uma reorientação das crenças fundamentais, já que a experiência sensível, que informa a percepção de que indivíduos são discretos, ou seja, separados e distintos uns dos outros, pode ser incorreta. O contínuo é, assim, a versão matemática do problema da unidade e da multiplicidade.

Este problema do um e dos muitos, que ganha na Metafísica de Aristóteles a sua mais geral e tradicional formulação, pode, portanto, ser resumido na seguinte pergunta: são todas as coisas uma unidade ou elas são múltiplas? ${ }^{13}$ Como vimos, tal pergunta geral pode ser reformulada e refeita de modos mais específicos, abrindo caminhos para investigações a respeito de problemas e questões progressivamente mais específicas. Finalmente, da escolha de Espinosa como representante da formulação teológica, de Descartes como expositor da formulação físico-científica

\footnotetext{
${ }^{13}$ Ver Halper (2009).
} 
e Leibniz como o da formulação matemática não se segue que Espinosa não tenha tratado da dimensão física ou matemática do problema nem que Descartes não tenha tratado da dimensão teológica ou matemática e muito menos que Leibniz tenha ignorado os aspectos teológicos e físicos da questão. ${ }^{14}$ Ao contrário, se é verdade que a metafísica do começo da modernidade é caracterizada pelo entrelaçamento desses três campos, a teologia se vale da matemática e da física, a matemática é explicada por conceitos teológicos e investigada na física, e a física ganha contornos tanto teológicos quanto matemáticos.

Portanto, tanto a metafísica de Espinosa quanto a de Descartes e Leibniz possuem os três contornos, ou seja, perpassam as questões teológicas, científicas e matemáticas. Esse entrelaçamento ocorre porque, no século XVII, este período de transição entre a escolástica tardia, o humanismo renascentista e a modernidade, tais campos eram parte integrante - e necessários - das explicações filosóficas. Essa abordagem compreensiva do conhecimento é evidenciada no chamado "esprit de système" da época (CASSIRER, 2009, p. 8). ${ }^{15}$ As investigações filosóficas eram conduzidas com o senso de que o conhecimento era

\footnotetext{
${ }^{14}$ A escolha metodológica do presente trabalho foi a de apresentar a formulação mais representativa de cada um destes campos para ilustrar como tais formulações são versões de um problema metafísico fundamental. Seria possível demonstrar o mesmo ponto analisando as três formulações em um mesmo autor, mas o argumento advindo de tal estratégia seria menos forte. Assim, procurando mostrar que os paradoxos em três autores diferentes se entrelaçam como versões de uma mesma questão, podemos daí derivar, com mais evidências, que tal questão também unifica as dimensões teológicas, científicas e matemáticas no interior da filosofia de cada um dos autores.

${ }^{15}$ A expressão é usada por Cassirer para caracterizar o Iluminismo nascente do século XVII em contraste com o Iluminismo mais expressivo do século XVIII. No século XVII, os sistemas eram valorizados em si mesmos, ou seja, havia um "esprit de système", uma defesa da abordagem sistemática, porque o sistema era por si só um indício de rigor e racionalidade. Já no século XVIII, segundo Cassirer, há um esforço de sistematização da filosofia, ou um "esprit systématique", que não se reduz à valorização dos sistemas em si mesmos, mas se expressa em um positivismo racional. Enquanto no século XVII havia a busca pela ordem da razão, de modo que essa busca era uma regra direcionadora do espírito, no século XVIII, acreditava-se que a razão iria mostrar sua própria força, ganhando clareza e perfeição na medida em que progrediria no conhecimento dos fatos. Ver a tese de Cassirer (1932, p. 8-9).
} 
um todo unificado e dado que as teorias sobre as coisas deveriam ser estruturadas de modo sistemático. ${ }^{16} \mathrm{~A}$ abordagem dos problemas filosóficos tende, ao longo da modernidade, a se afastar do âmbito da teologia e a oscilar entre a estratégia logicista (matemática) e a científica (física ou empírica), tornado-se cada vez mais especializadas em áreas determinadas e independentes umas das outras. No momento em que a modernidade é inaugurada, entretanto, o espírito de sistema prevalece. Tal inclinação pela sistematização é uma característica que torna mais claro o entrelaçamento entre os problemas teológicos, científicos e matemáticos das filosofias da época.

Para concluir, voltando à análise da natureza dos paradoxos realizada no início do trabalho, temos que esses paradoxos metafísicos podem ser lidos segundo as características que eles têm em comum com todo e qualquer paradoxo. Paradoxos ocorrem quando, ao utilizarmos o mesmo critério para interpretar separadamente A, B e para interpretar a conjunção de $\mathrm{A} \& \mathrm{~B}$, percebemos que, na verdade, há uma dissemelhança profunda entre A e B que não era aparente. Tais paradoxos demonstram a necessidade ou de se estabelecer distinções entre os termos e separálos de modo que não possam vir a ser interpretados em conjunto, ou de outro modo, procurar as semelhanças mais profundas entre tais termos e identificá-los a ponto de não haver mais ponto de contradição. Entretanto, nem sempre tal resolução é possível e os paradoxos descritos anteriormente exemplificam essa dificuldade. Nesses casos, resta aceitar o incômodo gerado e deixar que sua força se exerça no intelecto, para que, com o exercício da razão prevaleça, dentre os muitos, algum caminho. Em todo e qualquer tempo, há sempre o risco de o pensamento encontrar seus limites ao deter-se sobre paradoxos, mas também, com vimos acima, há a esperança de o pensamento expandir suas fronteiras e inaugurar

\footnotetext{
${ }^{16}$ Ver também o capítulo de Daniel Garber sobre os fundamentos da física. Ele afirma que "toda explicação sobre o mundo à volta eram incompletas se não tivessem uma grande imagem de pano de fundo onde estas explicações poderiam ser incluídas, uma imagem que muitas vezes incluía elementos tais como as categorias básicas da existência e a relação entre o mundo natural e deus. Muitos compartilhavam deste senso de que o conhecimento estava interconectado e sentiam a necessidade de encontrar um fundamento para a ciência que trata do mundo natural" (GARBER, 2008, p.21).
} 
novos tempos. Por isso, a captura, o interesse, ou mesmo a perturbação e o desconforto trazidos pelos paradoxos fazem deles a melhor forma de apresentação das questões filosóficas, já que, de antemão, garantem algum tipo de envolvimento intelectual. Ao contrário das perguntas tradicionais “o que é?” e "por quê?”, que podem ser ignoradas ou consideradas vazias, os paradoxos são capazes de capturar, imediatamente, o pensamento. Portanto, ainda que a razão se debruce sobre tais enigmas sem a garantia de que conseguirá resolvê-los, os paradoxos são a promessa de que, ao deter-se sobre eles, a razão pode assegurar a continuação indefinida de seu próprio movimento. ${ }^{17}$

\section{Referências}

ANSTEY, P. R.; SCHUSTER, J. A. The Science of Nature in the Seventeenth Century. Patterns of Change in Early Modern Natural Philosophy. Dordrecht, Netherlands: Springer, 2005.

ARTHUR, R. T. W. Leibniz. Cambridge: Polity Press, 2014.

ARTHUR, R. T. W. (Trad. e ed.). The Labyrinth of the Continuum: Writings on the Continuum Problem, 1672-1686. New Haven: Yale University Press, 2001.

BORGES, J.-L. Obras Completas. Buenos Aires: EMCE, 2011. 4 v.

CASSIRER, E. The Philosophy of the Enlightenment. New Jersey: Princeton University Press, 2009.

DESCARTES, R. Philosophical Writings. Translated by John Cottingham, et al. Cambridge: Cambridge University Press, 1985. v. 1-2.

EBETURK, E. Tracing the Footsteps of The young Leibniz in the Labyrinth of the continuum. 2008. Thesis (M. A.) - Middle East Technical University, Sept. 2008.

${ }^{17}$ Devo esta conclusão à pequena resenha de Borges ao livro Mathematics and Imagination, de Edward Kasner e James Newman, presente em suas obras completas. Borges termina a resenha deste livro sobre paradoxos enunciando o seguinte: "En Sumatra, alguien quiere doctorarse de advino. El brujo examinador le pregunta si será reprobado o si pasará. El candidato responde que será reprobado... ya se presiente la infinita continuación.” (BORGES, 2011, p. 560) 
FRAENKEL, C.; PERINETTI, D.; SMITH, J. E. H.(Ed.). The Rationalists Between Tradition and Innovation. New York: Springer, 2011.

FRAGOSO, E. A. R. A Definição de Deus na Ética de Benedictus de Spinoza. Kalagatos Revista de Filosofia do Mestrado Acadêmico em Filosofia da UECE, Fortaleza, v.2, n. 4, p.11-31, verão 2005.

GARBER, D.; AYERS, M. (Ed.). The Cambridge History of SeventeenthCentury Philosophy. Cambridge: Cambridge University Press, 1998.

GARBER, D. Physics and Foundations. In: PARK, K.; DASTON, L. (Ed.). Cambridge History of Science. Cambridge: Cambridge University Press, 2006. v. 3. Early Modern Science.

HALPER, E. One and Many in Aristotle's Metaphysics. Books alphadelta. Las Vegas: Parmenides Publishing, 2009.

KORICHI, M. Baruch Spinoza Lettres sur le mal Correspondance avec Blyenbergh. Barcelone: Folio Plus Philosophie, 2006.

LANDINI, G. Russell's Separation of the Logical and Semantic Paradoxes. Revue Internationale de Philosophie, Cairn.Info, v. 3, n. 229, p. 257-294, 2004.

LEIBNIZ, G. W. Discurso de Metafisica e outros textos. Apresentação e notas de Tessa Moura Lacerda. Tradução Marilena Chaú e Alexandre Cruz Bonilha. São Paulo: Martins Fontes, 2004.

NADLER, S. Spinoza, Leibniz and the Gods of Philosophy. In: FRAENKEL, C.; PERINETTI, D.; SMITH, J. E. H.(Ed.). The Rationalists Between Tradition and Innovation. New York: Springer, 2011.

PARK, K.; LORRAINE, D. (Ed.). The Cambridge History of Science Volume 3 Early Modern Science. Cambridge: Cambridge University Press, 2008.

PARKINSON, G. H. R.; MORRIS, M. (Trad. e ed.). Gottfried Wilhelm Leibniz: Philosophical Writings. London: J. M. Dent \& Sons, 1973.

QUINE, W. V. The Ways of Paradox. Cambridge: Harvard University Press, 1976.

RIESTERER, P. Lost in the Labyrinth: Spinoza, Leibniz and the Continuum. 2006. Thesis (M.A.) - McMaster University. August, 2006. 
RUSSELL, B. A Critical Exposition of the Philosophy of Leibniz. London: Routledge, 1992.

SLOWIK, E. "Descartes' Physics", The Stanford Encyclopedia of Philosophy (Summer 2014 Edition). Edward N. Zalta (Ed.). Disponível em: $<$ https://plato.stanford.edu/archives/sum2014/entries/descartesphysics/>.

SORENSEN, R. A Brief History of Paradox. Philosophy and the Labyrinths of the Mind. New York: Oxford University Press, 2003.

SPINOZA, B. The Collected Works of Spinoza. Edited and translated by Edwin Curley. Princeton University Press, 1985. v. 1.

SPINOZA, B. The Collected Works of Spinoza. Edited and translated by Edwin Curley. Princeton University Press, 2016. v. 2.

SPINOZA, B. Opera Posthuma, Amsterdam 1677. Riproduzione fotografica integrale a cura di Pina Totaro prefazione di Filippo Mignini. Quodlibet, 2008.

SPINOZA, B. Breve Tratado de deus, do homem e de seu bem-estar. Trad. Emanuel Angelo da Rocha Fragoso e Luiz Alberto Oliva. São Paulo: Ed. Autêntica, 2014.

SPINOZA, B. Ética. Trad. Tomaz Tadeu. Editora Autêntica, 2007.

SPINOZA, B. Pensamentos Metafísicos, Tratado da Correção do Intelecto, Ética, Tratado Político, Correspondência. Trad. Marilena Chauí, Carlos Lopes de Mattos, Joaquim de Carvalho e Manuel de Castro. São Paulo: Editora Abril Cultural, 1973. (Coleção Os Pensadores.)

Recebido em 20 de julho de 2017. Aprovado em 11 de setembro de 2017. 